\title{
PALABRA ABIERTA - EDUCACIÓN POPULAR, CONTEXTO LATINOAMERICANO Y EL LEGADO DE PAULO FREIRE
}

OSCAR JARA ${ }^{*}$

ORCID: https://orcid.org/0000-0002-6309-5567

RESUMEN: Se presentan cinco características que están marcando el contexto latinoamericano el día de hoy y ante ellas, se plantean seis desafíos para una educación popular transformadora inspirada en el pensamiento de Paulo Freire. Palabras clave: Educación popular. Paulo Freire. América Latina.

\section{OPEN WORD - POPULAR EDUCATION, LATIN AMERICAN CONTEXT AND THE LEGACY OF PAULO FREIRE}

ABSTRACT: This article presents five characteristics of the current Latin American context and, facing them, six challenges are proposed for a popular and transformative education inspired by Paulo Freire thought.

Keywords: Popular education. Paulo Freire. Latin America.

Hoy, primero de mayo, día internacional de los trabajadores y trabajadoras, quiero comenzar esta exposición pidiéndoles a todas y todos ustedes que enviemos un saludo especial, que llegue desde Belo Horizonte hasta Curitiba y podamos desear un Buen Día a un trabajador, a un luchador, a una persona que tanto ha dado para el avance de la justicia y la equidad en nuestra América Latina, José Ignacio Lula da Silva: ¡Buen Día Lula!.

Agradeciendo la oportunidad maravillosa de estar aquí en este importante evento internacional con tantas personas participando en las mesas de trabajo y las palestras y con gente tan especial como nuestra querida Nita Freire, saludo especialmente a la comisión organizadora y en ella a Julinho Diniz y Analise da Silva. Linda oportunidad de aprendizaje y de intercambio.

'Universidad de Costa Rica, San Pedro, Província de San José, Costa Rica.

"Educador Popular, Sociólogo. Doctor em educação pela Universidade de Costa Rica. Presidente do Conselho de Educação Popular de America Latina e o Caribe, CEAAL. Director do Centro de Estudos e Publicações Alforja, San Jose, Costa Rica. Correo electrónico:<oscar@cepalforja.org > . 


\section{¿DESDE DÓNDE HABLAMOS?}

Siempre es bueno preguntarnos: ¿Desde dónde hablamos? ¿Desde dónde vamos a abordar el tema: "El contexto latinoamericano y el legado de Paulo Freire?". Porque siempre hablamos desde algún lugar, desde una postura, en un momento histórico concreto que nos hace mirar las cosas de una determinada manera. Yo quiero hablarles desde mi pertenencia como educador popular que trabaja en una Ong el CEP ALFORJA de Costa Rica y también desde el CEAAL, un movimiento de educadoras y educadores populares comprometidos con las transformaciones en nuestra región. Les recuerdo que Paulo Freire fue, precisamente, el primer presidente del CEAAL en 1982, y eso significó desde entonces nuestro compromiso con su pensamiento y con los desafíos que ese pensamiento nos fue marcando a lo largo de los años.

Hablamos entonces desde las reflexiones y aspiraciones de educadoras y educadores populares que cada día, en muy distintos lugares, tratan de aportar a fortalecer el protagonismo de la gente, de las clases populares, en los procesos de cambio social de nuestra región. También desde sus preocupaciones, dolores y esperanzas.

\section{EL CONTEXTO LATINOAMERICANO}

Quisiera -de manera rápida- presentar cinco aspectos que me parece que son determinantes en el actual momento histórico de nuestra región:

\section{El fundamentalismo del mercado.}

No sólo las políticas neoliberales están siendo predominantes en nuestra región. Es también una manera de pensar individualista y consumista en la que todo ese vuelve mercancía y es la lógica hegemónica para las relaciones económicas, sociales, políticas y culturales. También se vende el conocimiento a través de múltiples formas de privatización y de control. El mercado y el lucro es el valor predominante y por lo tanto, es la ética que gobierna los bolsillos, las mentes y los corazones.

\section{Hay una ofensiva de restauración conservadora}

Luego de intensos procesos de búsqueda de cambio social que se vivieron en los últimos 15 años para reducir las desigualdades de América Latina, con cambios de gobierno y políticas sociales en Brasil, Argentina, Venezuela, Uruguay, Bolivia, Ecuador, Nicaragua, 
El Salvador y movilizaciones importantes en otros países, hoy estamos ante una ofensiva brutal que busca regresar al pasado en beneficio de los tradicionales sectores dominantes.

Esta ofensiva está significando una importante pérdida de derechos conquistados, aumento de las desigualdades y de la exclusión social, criminalización de las protestas, mayor depredación de la naturales y aumento de la represión.

\section{Nuestras sociedades se han polarizado}

Esta ofensiva, que está buscando retroceder en la historia, aunque ha utilizado mecanismos de la democracia formal, es profundamente antidemocrática porque está cargada de agresividad, de violencia, de irrespeto, de negación de los derechos ciudadanos de todas las personas. Así, cada vez más, nuestras sociedades se polarizan y los grupos sociales se enfrentan en posturas cada vez más irreconciliables.

\section{Se refuerza la lógica dominante}

Debido a lo anterior, en el momento actual, las fuerzas sociales, políticas e ideológicas de las empresas, partidos y medios de comunicación dominantes refuerzan la lógica hegemónica que es capitalista, patriarcal, extractivista, racista y colonial. Y esta lógica unifica todos estos elementos en una amalgama ideológica, bajo una sola forma de dominación, que busca imponerse bajo un discurso y un disfraz falsamente democrático.

\section{Se refuerza una subjetividad coherente con esta propuesta de dominación}

La ofensiva conservadora resalta e impone una subjetividad individualista, consumista, conformista, pasiva e intolerante. Cada quien busque salvarse por su cuenta y aplastando a los demás si es necesario, promoviendo la resignación ante esta realidad que aparece como la única posible y no tiene sentido querer cambiarla.

Es una subjetividad también fundamentalista y mesiánica en la que se utilizan argumentos religiosos para justificar las políticas neoliberales: la familia tradicional, posturas homofóbicas, el enfrentamiento a la inventada "ideología de género", la defensa de la "escuela sin partido" y otros argumentos como identificar a las personas defensoras del ambiente como "ecoterroristas".

Y así, todo se les vuelve coherente para justificar el retorno al viejo orden y evitar que nuestras sociedades cambien: la economía, las 
políticas sociales, los argumentos ideológicos, la moral religiosa, la utilización de los poderes judiciales y también, para quien no se resigna, la represión.

\section{¿CUÁLES SON LOS DESAFÍOS DE ESTE CONTEXTO PARA LOS PROCESOS Y MOVIMIENTO DE EDUCACIÓN POPULAR INSPIRADOS EN FREIRE?}

a) Los procesos de educación popular, inspirados en Paulo Freire, enfrentamos este paradigma neoliberal, conservador, con otro paradigma ético, político y pedagógico.

Una deformación muy común ha sido considerar el pensamiento de Paulo Freire como una "metodología". No. El pensamiento de Paulo Freire es una filosofía educativa centrada en las personas como sujetos de transformación de la historia. Es un paradigma ético, político y pedagógico emancipador, liberador que, claro tiene también propuestas metodológicas coherentes con él, pero no se reduce a ellas.

Se trata, entonces, en el pensamiento freiriano, de otros valores: la justicia, la equidad, la solidaridad, el respeto por las demás personas, el diálogo horizontal, la problematización y la actitud crítica entre otros.

Por eso, ante este contexto de restauración conservadora y fundamentalista, oponemos otro paradigma, otra lógica, otros valores.

b) Ante esta ofensiva antidemocrática, los procesos de educación popular oponemos un elemento central de la propuesta freiriana: la radicalidad democrática. En todos los espacios, en todos los terrenos. En una propuesta educativa democrática y democratizadora que, por eso mismo, contribuye a construir relaciones democráticas en la vida económica, social, política y cultural.

Frente a una educación domesticadora, Freire opone una educación democrática, crítica, instigadora, inconforme. Una pedagogía de la liberación, de la esperanza, de la indignación, de la autonomía, de los sueños posibles.

c) Los retos del actual contexto suponen también grandes desafíos para la formación de las educadoras y los educadores. ¿Queremos ser objetos transmisores de las políticas educativas que nos imponen o sujetos creadores de políticas nuevas? ¿Para qué nos formamos? ¿Para ser instrumentos de la pasividad, la resignación, el conformismo, el individualismo o el consumismo o para ser instrumentos de dignidad, rebeldía, crítica, solidaridad? ¿Para ser instrumentos de "adaptación” a 
la lógica dominante o para ser sujetos de "transformación y creación" de una nueva manera de ver el mundo?.

d) Ante estos retos del contexto, ¿nuestro papel es ser facilitadores o facilitadoras? Muchas veces se utiliza la idea que el educador o educadora popular, para no ser autoritarios, verticales, impositivos, debería verse como un "facilitador" o una "facilitadora". Y, si bien la idea de no ser vertical es positiva, la noción de "facilitar" puede traer un engaño: nos puede alejar del grupo y del proceso educativo, porque estamos ahí sólo para "facilitar" el proceso y no comprometernos con él. Incluso peor: nos puede reforzar la idea manipuladora de que "yo, ya sé este tema, ya lo domino, pero ahora se lo voy a "facilitar" al grupo" (o sea, hacérselo fácil). Entonces, yo quisiera reforzar una idea freiriana que poco se ha divulgado: la idea del educador o educadora como "desafiador" o "desafiadora", es decir, como quien tiene una responsabilidad que es desafiar al colectivo a trabajar un proceso crítico, pero en el cual, él o ella también son desafiados por el grupo. Así, el educador popular, desafiador, está desafiado en cada momento del proceso y se construye como tal en conjunto con el grupo.

e) Otro legado que nos deja Freire y que tiene más importancia en el actual contexto, es la fundamental importancia de la reflexión crítica sobre la propia práctica. Considerar que la educadora o educador, tenemos en nuestra propia práctica -que no es rutinaria, aburrida, pasiva, sino creadora, crítica, llena de innovaciones posibles- la fuente principal de nuestra formación permanente.

Las educadoras o educadores populares freirianas y freirianos estamos en proceso de formación todo el tiempo. Nunca terminamos de formarnos. Y precisamente lo que nos puede ayudar a formarnos, en una práctica permanentemente innovadora y creativa, es la reflexión crítica sobre esa práctica. De ahí, que cada vez más, la sistematización de experiencias esté siendo asumida como un factor fundamental en los procesos de educación popular, que nos impide la pasividad, el conformismo o la rutina, sino que siempre nos da la capacidad de enriquecer la teoría educativa y la nueva práctica.

f) Finalmente, todos estos desafíos que nos coloca nuevamente Freire ante el actual contexto, no para que lo repitamos a él, sino para que lo "reinventemos", implican que estemos en disposición a vivir nuestra práctica política-pedagógica, con toda la complejidad de sus tensiones y contradicciones. Con todas las dimensiones de integralidad que la constituyen. No es fácil, ni siempre estaremos en lo cierto, pero por eso tenemos que afirmarnos en el sentido ético de la coherencia. 
Decía Paulo que la virtud no era "ser coherente", sino que era "la búsqueda de coherencia". Pues señalaba que "mi coherencia de hoy, puede ser mi incoherencia de mañana", y replanteaba: "pero también mi incoherencia de hoy, puede ser mi coherencia de mañana".

A eso nos invita este legado freriano que debemos recrear cada día en nuestras prácticas. Pues esta utopía que queremos conseguir, no está esperándonos al final de ningún camino, esa utopía debe ser el motor que nos hace caminar poniéndola en práctica en cada paso.. Esa búsqueda de coherencia entre los valores que queremos conseguir en la historia y nuestra práctica cotidiana es lo que nos permitirá ser sujetos protagonistas de transformación.

Permítanme terminar con un poema y una canción: El poema, es un extracto de "canción obvia" de Freire y dice:

\section{“Quem espera na pura espera}

Vive um tempo de espera vã.

$$
\text { (...) }
$$

...Não te esperarei na pura espera

porque o meu tempo de espera é um tempo de quefazer.

$$
\text { (...) }
$$

Estarei esperando tua chegada

Como o jardineiro prepara o jardim

Para a rosa que se abrirá na primavera"

Y la canción, de Luis Enrique Mejía Godoy de Nicaragua: "Tengo América en mi voz"

\section{TENGO A AMÉRICA EN MI SANGRE TENGO A AMÉRICA EN MI PIEL, TENGO A AMÉRICA EN MIS OJOS, TENGO A AMÉRICA EN MI VOZ!}

Yo soy de este continente de pájaros insurrectos que en medio de las tormentas su propia vida defiende,

Soy indio, negro y mestizo hijo de un tiempo feroz ¡cargamos muchas historias y levantamos la voz! 
Marimba, quena y zampoña flauta de barro y tambor Guitarra de Andalucía que el Caribe la preñó Y millones de habaneras, calypsos, cumbia y reggae, boleros, sones y tangos que esta América parió!

Soy América Latina, que de este lado del mar hace más de quinientos años lucha por su libertad Tanto oro se llevaron por la tierra y por el mar Robaron nuestras riquezas, ipero no la dignidad!

\section{REFERENCIAS}

FREIRE, P. Pedagogia da Indignação. São Paulo: Siglo XXI, 2000.

JARA, O. La Educación Popular, historia y claves éticas, políticas y pedagógicas. San José, Costa Rica. CEP Alforja, CEAAL, Intered, Alboan, 2018.

Presentado: 04/10/18

Aprobado: 06/02/2019

Dirección postal:

APARTADO POSTAL 1272- 2050

San José, Costa Rica

Centroamérica 